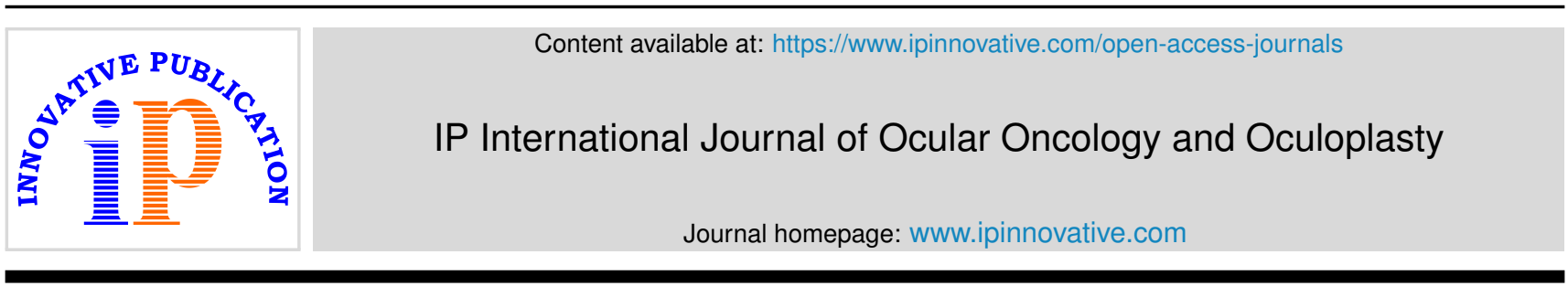

Original Research Article

\title{
Ocular side effects of anti-tubercular drugs in patients receiving Anti-Tb treatment at tertiary care center
}

\author{
Trupti M Solu ${ }^{1}$, Kruti Panchal ${ }^{1, *}$ \\ ${ }^{1}$ Dept. of Ophthalmology, Goverment Medical College, Surat, Gujarat, India
}

\section{A R T I C L E I N F O}

\section{Article history:}

Received 12-08-2020

Accepted 17-08-2020

Available online 03-09-2020

\section{Keywords:}

Tuberculosis

Ethambutol

Optic neuropathy

Visual field defects

Colour vision

\begin{abstract}
A B S T R A C T
Introduction: India is among the countries that carry the highest burden for tuberculosis. Antitubercular drugs are frequently associated with ocular toxicity. Among ATT, ethambutol is the most commonly implicated drug causing optic neuropathy. For assessing spectrum of ATT induced ocular toxicity, clinical presentation, monitoring, and preventive measures a prospective observational follow up study was conducted.

Materials and Methods: A newly diagnosed drug susceptible pulmonary tuberculosis patients referred to ophthalmology OPD during a study period from May 2018 - October 2019 at a tertiary care hospital. The detailed history, best corrected visual acuity, fundus examination, color vision test and visual fields were carried out in all patients at the start of treatment and thereafter every month up to 6 months after initiation of ATT.

Results: During six month follow up study, out of 94 study participants, 14 eyes of seven patients $(7.44 \%)$ had drop in visual acuity from baseline $(\mathrm{p}$ value $=0.03)$. Total 10 eyes of five patients $(5.32 \%)$ had developed colour vision abnormality $(\mathrm{p}=0.001)$ and 8 eyes of four patients had developed optic disc changes from baseline. Visual field defects were noted in ten $(5.32 \%)$ eyes $(\mathrm{p}=0.001)$. In our study ATT related ocular toxicity was found in $5.32 \%$ on standard HRZE drug regimen.

Conclusion: The course of ethambutol-induced ocular toxicity is unpredictable. The early recognition of ocular toxicity is paramount to prevent irreversible visual loss.
\end{abstract}

(C) 2020 Published by Innovative Publication. This is an open access article under the CC BY-NC license

(https://creativecommons.org/licenses/by-nc/4.0/)

\section{Introduction}

Tuberculosis (TB) has been present since $460 \mathrm{BC}$, as the most widespread disease of the time, and it was fatal. The causative organism of TB is Mycobacterium tuberculosis which is a slow-growing bacterium, acquired by deposition of aerosol droplets via inhalation. ${ }^{1} \mathrm{~TB}$ is still the most common infectious disease and a major public health problem, infecting millions of people worldwide. India accounts for about a quarter of the global TB burden. ${ }^{2}$ Carr and Henkindin 1962 first described the ocular side effect of Ethambutol. ${ }^{3}$ Ethambutol is generally well tolerated, but it is known to cause optic neuritis, more specifically retrobulbar neuritis. ${ }^{4}$ Ethambutol causes two

\footnotetext{
* Corresponding author.

E-mail address: kruti_panchal13@yahoo.com (K. Panchal).
}

types of optic neuritis: one is axial neuritis (central) and the other one is paraxial neuritis (peripheral). The central fibers of the optic nerve are most commonly affected, causing blurred vision, decreased visual acuity, central scotomas, and often loss of the ability to detect red and green. The peripheral fibers of the optic nerve are less commonly involved, so that visual acuity and colour vision may not be affected, but peripheral constriction of the visual fields occurs. ${ }^{5}$ The exact pathophysiology of ethambutol optic neuropathy has not yet been identified. Mitochondrial disturbance, the zinc-chelating effect and its metabolite are the possible underlying mechanisms. ${ }^{6}$ EMB toxicity is related to the dose and duration of treatment and in most of the cases it is reversible, but may occasionally become irreversible resulting in permanent visual impairment especially in the older population. It 
has been said that there is no so-called "safe-dosage" for EMB. ${ }^{7}$ Isoniazid can rarely cause retro bulbar neuritis. ${ }^{4}$ Rifampicin can produce orange colour tears and orange staining of contact lenses. ${ }^{8}$ There are a number of uncertain and difficult areas in the recommendation of preventive measures against drug-induced ocular toxicity during antiTB treatment. The management of EMB induced optic neuropathy involves immediate discontinuation of the drug. ${ }^{4}$ If the optic neuritis fails to improve within 6 weeks after stopping EMB, INH should also be stopped. Pyridoxine $25-100 \mathrm{mg} /$ day may be considered in isoniazid induced toxic neuropathy, particularly for those with risk factors like malnutrition, alcoholics. ${ }^{7}$

\section{Materials and Methods}

This study is an observational follow up study. Initially 100 patients of newly diagnosed drug susceptible pulmonary tuberculosis, referred to ophthalmology OPD in a tertiary care hospital were examined. Out of 100 study participants, six participants were lost to follow up after few months of DOTs therapy, hence excluded. Thus total 94 participants had completed prescribed number of follow ups and contributed in follow up study. All the patients enrolled in the study were evaluated during a period from May 2018 - October 2019. These patients were examined and investigated thoroughly as per the protocol after approval from the institutional ethical committee, at ophthalmic OPD using airborne precautions.

\subsection{Inclusion criteria}

New cases of drug susceptible pulmonary TB receiving standard HRZE treatment regimen under DOTs therapy were included. Standard HRZE ATT regime $(\mathrm{H}=$ isoniazid, $\mathrm{R}=$ rifampicin, $\mathrm{Z}=$ pyrazinamide, $\mathrm{E}=$ Ethambutol) followed $\mathrm{H}$ : $4-6 \mathrm{mg} / \mathrm{kg}$ body weight, $\mathrm{R}: 8-12 \mathrm{mg} / \mathrm{kg}$ body weight, Z: $20-30 \mathrm{mg} / \mathrm{kg}$ body weight, E: $15-25 \mathrm{mg} / \mathrm{kg}$ body weight. Adult patients (age $>18$ years) and those who gave informed written consent to participate in the study were included.

\subsection{Exclusion criteria}

All MDR-TB and XDR-TB category patients and who has received anti TB drugs in past. Patients having any major systemic illness (Diabetes mellitus, Hypertension, renal disease, demyelinating disease) and patients having preexisting posterior segment pathology that might affect visual acuity like diabetic retinopathy, retinitis pigmentosa, retinal detachment, optic atrophy etc. Patients having mature cataract or dense ocular media opacity. Patients with preexisting colour vision defects. Patients who are on medications which can cause optic neuropathy like phosphodiesterase type 5 (PDE-5) inhibitors, amiodarone, linezolid as well as patients who are on medications that can affect colour vision like oral contraceptives, digoxin, indomethacin were excluded form study.

\subsection{Methodology}

After initial enrolments, all patients of newly diagnosed pulmonary TB on standard HRZE regimen were examined thoroughly before initiating ATT and thereafter every month up to 6 months during a period from May 2018 to October 2019. Socio demographic data with patient's personal identification information was recorded. Detailed clinical history including dietary habit, addiction to tobacco, alcohol, any other medication, any ocular trauma or surgery was noted. External examination of eyes and pupillary reflex were noted on torch light examination. All the patients were evaluated for best corrected visual acuity by illuminated Snellen chart for 20 feet distance. Visual acuity loss was counted if it had exceeded two lines in Snellen chart between each monthly ophthalmic examination in the absence of other causal factors. Colour vision was assessed using Ishihara chart. Subjects were tested while wearing best correction. The patients are made to read the plates in adequate daylight held at distance of $75 \mathrm{~cm}$ from the subject and tilted so that the plane of the paper was perpendicular to the line of vision. Out of plates 121 if $>13$ plates are read correctly, the colour vision was regarded as normal. If only 9 or fewer plates were read correctly, colour vision was regarded as deficient. Slit lamp biomicroscopy was performed with Appasamy AIA-11 5S slit lamp, for anterior segment evaluation. Detailed fundus examination was done with indirect ophthalmoscope and slit lamp bio microscopy with +78D lens (Volk) for posterior segment pathology. Visual field testing was done using the Carl Zeiss Meditec HFA 2 Humphrey field analyzer with 30-2 threshold programme, with dim ambient light source with full refractive correction. Examination was repeated until reliable fields were obtained. Only those fields that were reliably performed were included in the analyses. All participants were called every month for follow up detailed ophthalmic examination up to 6 months. Differences between baseline and follow\&\#8209;up findings were noted. Statistics analysis has been done using - Epi info 7 \& SPSS v19. The McNemar Chi-square test was applied to compare statistical difference in visual function among tuberculosis patients before and after initiating of ATT. The $P$ value equal to or less than 0.05 was considered statistically significant.

\section{Results}

Initially 100 patients of newly diagnosed drug susceptible pulmonary tuberculosis were examined. Out of 100 study participants, six participants did not turn up for follow up after few months of DOTs therapy, hence excluded. Thus total 188 eyes of 94 study participants were analyzed. Mean 
age of the patients is 33.66 year with maximum number of patients being in age group $18-30$ years $(54.25 \%)$. There were $52(55.32 \%)$ males and $42(44.68 \%)$ females.

Out of 188 eyes of 94 participants, 178 eyes of 89 patients had best corrected visual acuity of $20 / 20$ on baseline examination while 10 eyes of five patients had baseline best corrected visual acuity ranging from 20/30 to 20/60; which was found to be due to cataract in these patients. Thus baseline best corrected visual acuity was ranged from $20 / 20$ to $20 / 60$. All the patients were followed up at monthly interval up to 6 months and their visual acuity was tested, during which we found that decline in visual acuity from baseline was seen in 14 eyes of seven patients $(7.44 \%)$ in which 4 eyes of two patients had drop in visual acuity at $4^{\text {th }}$ month follow up, 8 eyes of four patients had drop in visual acuity at $5^{\text {th }}$ month follow up and 2 eyes of one patient at $6^{\text {th }}$ month follow up. (Table 1 . Visual acuity changes from baseline in participants during six month follow up study) On using McNemar Chi-Square Test these difference of visual acuity at baseline and at $6^{\text {th }}$ month from baseline were found (Chi-Square value -4.3 , $\mathrm{p}$ value -0.03 ) statistically significant.

Baseline colour vision was found to be normal in 188 eyes of 94 study participants. Colour vision was assessed using Ishihara colour vision plates. During study, it was observed that out of 188 eyes, 10 eyes of five patients $(5.32 \%)$ showed colour vision abnormality at the end of 6 month follow up. These differences in colour vision status between baseline and at the end of $6^{\text {th }}$ month from baseline ( $\mathrm{p}=0.001$, Chi square value is 10.56 ) were statistically significant. (Table 2 . Colour vision changes in study participants during six month follow up.) It was observed that among 188 eyes, eight eyes of four patients had developed optic disc changes from baseline at the end of six month follow up. Out of these eight eyes, four eyes of two patients $(2.12 \%)$ had temporal pallor and other four eyes of 2 patients $(2.12 \%)$ had early disc edema.

No visual field changes were found on baseline evaluation in all 188 eyes. At the end of six month follow up study 10/188 (5.32\%) eyes developed changes in their visual fields from baseline. Out of 10 eyes, four eyes had developed changes at $4^{\text {th }}$ month follow up and six eyes had developed changes at $5^{\text {th }}$ month follow up. The most common defect seen was cecocentral scotoma in four $(2.12 \%)$ eyes out of 188 eyes. Other defects seen were peripheral constriction $(1.06 \%)$, peripheral defect in different quadrant $(1.06 \%)$ and central scotoma $(1.06 \%)$. (Table 3 . Visual field changes from baseline in study participants during six month follow up.) These differences in visual field defects from baseline and after six months from baseline $(p=0.001$ and Chi square value $=9.7$ ) were statistically significant . Fourteen eyes of seven participants had developed ocular manifestations attributed to ATT toxicity, out of which two patients had developed manifestations at $4^{\text {th }}$ month follow up after start of ATT, four patients at $5^{\text {th }}$ month follow up and one patient at $6^{\text {th }}$ month follow up. Thus average duration for development of ocular manifestations attributed to ATT toxicity was 5th month after initiating ATT. (Figure 1)

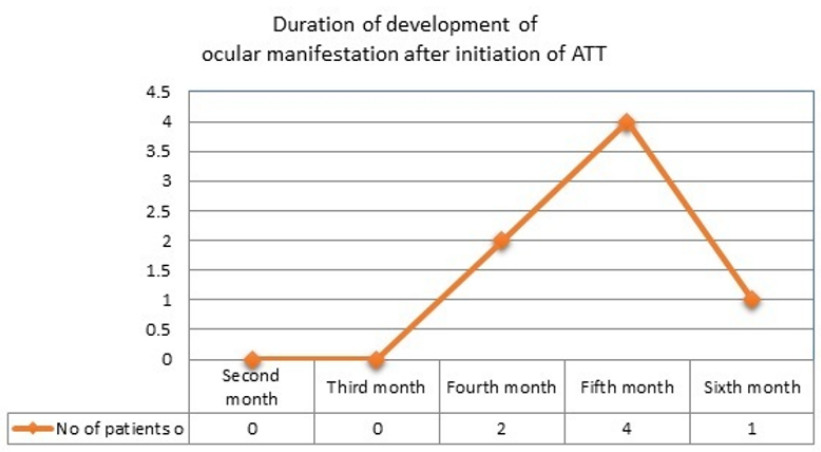

Fig. 1: Line chart showing duration of development of ocular manifestation after initiation of ATT.

\section{Discussion}

Ethambutol is being used to treat tuberculosis since the 1960s. The potential for visual impairment was recognized soon after its introduction. The incidence of EMB ocular toxicity has been reported in various ways. Leibold JE et al reported the incidence of ethambutol toxicity depending on dosage. ${ }^{9}$ It was found to be $18 \%$ in patients taking ethambutol more than $35 \mathrm{mg} / \mathrm{kg} / \mathrm{day}, 5 \%$ in patients on $25 \mathrm{mg} / \mathrm{kg} /$ day, $3 \%$ among those on $20 \mathrm{mg} / \mathrm{kg} /$ day while negligible toxicity was seen in patients taking ethambutol $15 \mathrm{mg} / \mathrm{kg} /$ day stressing the importance of dosage on toxicity. Polak BC et alhad reported that Ethambutol causes optic neuropathy in 1-5\% of patients using antituberculous medications. ${ }^{10}$ Clarke et al in 1972 stated that a cumulative dose of $150 \mathrm{~g}$ is considered critical dose for ethambutol toxicity ${ }^{11}$. Citron observed that optic nerve toxicity developed usually after two months of therapy. ${ }^{5}$ This was also evident in present study.

In our study colour vision was tested with Ishihara pseudo isochromatic colour vision test while in Garg P et al study colour vision was tested using both Ishihara and Farnsworth D-15 colour vision test. ${ }^{12}$ In the study; 128 eyes of 64 patients of category 1 and 2 were evaluated, of which colour vision abnormalities were noted in 16 eyes of eight patients ( $p$ value $=0.003$ ). Out of these 16 eyes, four eyes showed impairment in red-green colour perception and the others showed impairment in blue-yellow colour perception. All abnormalities were noted by Farnsworth Panel D-15 test, while the Ishihara pseudo isochromatic test showed abnormality in only one participant. Since present study was done using Ishihara colour plates, the subtle colour vision defects may not be detected. Wong JKW et al in 2013 also demonstrated that Farnsworth D-15 hue test appears to be 
Table 1: Visual acuity changes from baseline in participants during six month follow up study.

\begin{tabular}{lcccc}
\hline Visual acuity & $\mathbf{2 0 / 2 0}$ & $\mathbf{< 2 0 / 2 0}$ to $\mathbf{2 0 / 6 0}$ & $\mathbf{< 2 0 / 6 0}$ to 20/200 & $\mathbf{< 2 0 / 2 0 0}$ \\
Baseline & $178(94.68 \%)$ & $10(5.32 \%)$ & 0 & 0 \\
$1^{\text {st }}$ month follow up & $178(94.68 \%)$ & $10(5.32 \%)$ & 0 & 0 \\
$2^{\text {nd }}$ month follow up & $178(94.68 \%)$ & $10(5.32 \%)$ & 0 & 0 \\
$3^{\text {rd }}$ month follow up & $178(94.68 \%)$ & $10(5.32 \%)$ & $2(1.06 \%)$ & 0 \\
$4^{\text {th }}$ month follow up & $174(92.55 \%)$ & $12(6.38 \%)$ & $8(4.25 \%)$ & 0 \\
$5^{\text {th }}$ month follow up & $166(88.29 \%)$ & $14(7.44 \%)$ & $8(4.25 \%)$ & 0 \\
$6^{\text {th }}$ month follow up & $164(87.23 \%)$ & $16(8.51 \%)$ &
\end{tabular}

Table 2: Colour vision changes in study participants during six month follow up.

\begin{tabular}{lc}
\hline Colour vision & No of new eyes affected \\
Baseline & 0 \\
$1^{\text {st }}$ month follow up & 0 \\
$2^{\text {nd }}$ month follow up & 0 \\
$3^{r d}$ month follow up & 0 \\
$4^{\text {th }}$ month follow up & $4(2.12 \%)$ \\
$5^{\text {th }}$ month follow up & $6(3.19 \%)$ \\
$6^{\text {th }}$ month follow up & 0 \\
Total no of New eyes affected & $10(5.32 \%)$
\end{tabular}

Table 3: Visual field changes from baseline in study participants during six month follow up.

\begin{tabular}{lcccc}
\hline Perimetry & Cecocentral scotoma & $\begin{array}{c}\text { Peripheral } \\
\text { constriction }\end{array}$ & $\begin{array}{c}\text { Peripheral defects in } \\
\text { different quadrants }\end{array}$ & $\begin{array}{c}\text { Bitemporal } \\
\text { hemianopia }\end{array}$ \\
Baseline & 0 & 0 & 0 & 0 \\
1 Month followup & 0 & 0 & 0 & 0 \\
2 Month followup & 0 & 0 & 0 & 0 \\
3 Month followup & 0 & 0 & 0 & 0 \\
4 Month followup & 0 & $2(1.06 \%)$ & $2(1.06 \%)$ & 0 \\
5 Month followup & $04(2.12 \%)$ & 0 & 0 & 0 \\
6 Month followup & 0 & 0 & & 0 \\
Total no of new eyes affected $10(5.32 \%)$ & & & \\
\hline
\end{tabular}

more sensitive than the Ishihara pseudo-isochromatic plates in detecting colour defects as an initial subjective screening tool for suspected ethambutol-related optic neuropathy. ${ }^{13}$

In our study $10 / 188(5.32 \%)$ eyes developed visual field defects, in which the most common defect seen was centrocecal scotoma (2.12\%). Bharamshetter RSconducted a study in which 160 eyes of 80 patients who were started on ATT under RNTCP were analyzed. ${ }^{14}$ Visual field defects were seen in $10(6.25 \%)$ eyes out of 160 eyes, in which $(40 \%)$ had centrocecal defects, $(40 \%)$ central defect, $(20 \%)$ had paracentral defects and $(20 \%)$ had nerve fiber defect. It was concluded in study that the field defects were dose dependent and statistically significant at the level of $\mathrm{p}<0.001$. In Mahrukh et al study, 198 eyes of 100 patients (two patients were one eyed) were analyzed and at the end of two months of ATT. ${ }^{15}$ It was seen that $27 / 198(13.63 \%)$ eyes developed changes in their visual fields. The most common defect seen was the peripheral defects in different quadrants $(8.1 \%)$. Other defects seen were peripheral constriction of the isopter $(3.03 \%)$, central scotoma (1.01\%) and bitemporal hemianopia (1.01\%). Garg
$\mathrm{P}$ also noted in his study that four patients had developed field defects $(6.3 \%)$ after 2 months of ATT. ${ }^{12}$

There is not a single simple diagnostic test that can be confirming or diagnostic for ATT toxicity. For our patients, the diagnosis EMB ocular toxicity was based on new onset of ocular symptoms compatible with ATT-related toxicity such as diminished visual acuity from baseline, altered colour vision perception, development of visual field defects and lack of an alternative explanation for the new ocular symptoms. These all three parameters of optic nerve function were taken into account to clinically diagnose a case of toxic optic neuropathy related to ATT. Out of 14 eyes of seven patients who developed changes from baseline, five patients were diagnosed to have drug induced toxic optic neuropathy taking all three parameters of optic nerve function. In rest two patients, one had decline of three line in Snellen's visual acuity chart from baseline, but other parameters were within normal limits. Other patient had two line decline of visual acuity from baseline, but other parameters were within normal limits. In these two patients decline in visual acuity could be attributed to any other 
causal factors like patient fatigue, lack of cooperation from patient, and technical errors. A regular follow up of these patients was done to see development of any changes in visual fields or colour vision. Thus in present study out of 188 eyes, 10 eyes $(5.31 \%)$ had shown Ethambutol toxicity on standard drug dosage of $(20+3.0 \mathrm{mg} / \mathrm{kg} /$ day $)$. Bobrowitz et al in his study also concluded that fluctuations in the reading of the snellen's eye chart probably do not reflect the side effect of the drugs, but rather the influence of other factors. ${ }^{16}$ Further, he emphasized that a drop in visual acuity from optic nerve or retinal damage would be expected to show associated changes in the visual field pattern. If this did not take place, there was no certain visual toxicity in the cases.

Limitations of study: In present study colour vision was assessed using Ishihara colour plates. Colour vision assessment with both Ishihara and Farnsworth D-15 hue test will be far more sensitive and yield better results in identifying drug induced colour vision defects.

\section{Conclusion}

In study of evaluation of visual function in patients receiving ATT at recommended doses, we found that ocular toxicity was seen in a significant number of patients $(5.31 \%)$. The ocular toxicity of ethambutol in our patients had manifested in the form of changes in visual acuity, colour vision, visual field and fundoscopy picture. We conclude that mandatory ophthalmic examination using sensitive indicators at monthly intervals is paramount and that, along with discontinuation of the offending drug when possible, constitutes the basis of treatment of drug-induced optic neuropathy in such patients. There is a requisite to formulate guidelines for mandatory baseline ophthalmic evaluation before initiation of treatment and then at regular intervals throughout the treatment. Educating patients about toxicity of ethambutol is a crucial factor in treatment of tuberculosis.

\section{Source of Funding}

None.

\section{Conflict of Interest}

None.

\section{References}

1. Jorgensen JH, Turnidge JD. Antimicrobial agents and susceptibility testing. In: Murray PR, editor. Manual of clinical microbiology. Washington, DC: ASM Press; 1995. p. 1497-1662.

2. Kanabus A. Information about Tuberculosis, Global Health Education; 2018. Available from: www.tbfacts.org.

3. Carr RE, Henkind P. Ocular manifestations of ethambutol: Toxic amblyopia after administration of an experimental antituberculosis drug. Arch Ophthalmol. 1962;67:566-71.

4. Kokkada SB, Barthakur R, Natarajan M, Palaian S, Chhetri AK, Mishra P, et al. Ocular side effects of antitubercular drugs-a focus on prevention, early detection and management. Kathmandu Univ Med $J$ (KUMJ). 2005;3(4):438-41.

5. Citron KM, Thomas GO. Ocular toxicity from ethambutol. Thorax. 1986;41(10):737-9.

6. Makunyane P, Mathebula S. Update on ocular toxicity of ethambutol. Afr Vis Eye Health. 2016;75:1-4.

7. Preventive measures against drug-induced ocular toxicity during antituberculous treatment (general recommendations). Annual Report. Hong Kong: Department of Health; 2002.

8. Muntingh GL. Drug and Contact Lens Interactions. South Afr Family Pract. 2005;47:24-8.

9. Leibold JE. The ocular toxicity of ethambutol and its relation to dose Ann New York Acad Sci. 1966;135(2):904-9.

10. Polak BCP, Leys M, van Lith GHM. Blue-Yellow Colour Vision Changes as Early Symptoms of Ethambutol Oculotoxicity. Ophthalmol. 1985;191(4):223-6.

11. Clarke GBM, Cuthbert J, Cuthbert RJ, Lees AW. Isoniazid plus ethambutol in the initial treatment of pulmonary tuberculosis. $\mathrm{BrJ}$ Dis Chest. 1972;66:272-6.

12. Garg P, Garg R, Prasad R, Mishra AK. A prospective study of ocular toxicity in patients receiving ethambutol as a part of directly observed treatment strategy therapy. Lung India. 2015;32(1):16-29.

13. Wang JK, Yau GS, Lee JW, Yuen CY. Detection of early ethambutol ocular toxicity: Ishihara pseudoisochromatic plates versus the Farnsworth D-15 hue test. J Neurophysiol Neural Disord. 2014;1(102):1-4.

14. Bhramshetter RS. Visual Field defects in patients of tuberculosis on ethambutol. J Evid Based Med Health Care. 2017;4(3):1323-7.

15. Mahrukh AA, Mohd B, A. Visual field changes in patients receiving antitubercular drug therapy at tertiary care hospital: an analytical observational study. Int J Contemp Med Res. 2017;4(2):346-9.

16. Bobrowitz ID, Robins DE. Ethambutol-isoniazid versus PASisoniazid in original treatment of pulmonary tuberculosis. . Am Rev Respir Dis. 1967;96:428-38.

\section{Author biography}

Trupti M Solu Additional Professor

Kruti Panchal Resident

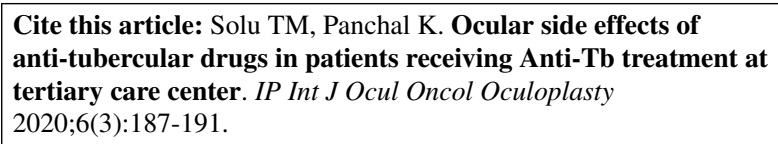

